\title{
Looking for differences in wood properties as a function of the felling date: lunar phase-correlated variations in the drying behavior of Norway Spruce (Picea abies Karst.) and Sweet Chestnut (Castanea sativa Mill.)
}

\author{
Ernst Zürcher $\cdot$ R. Schlaepfer $\cdot$ M. Conedera • \\ F. Giudici
}

Received: 30 September 2008/Revised: 4 July 2009/Accepted: 27 July 2009/Published online: 26 August 2009 (c) Springer-Verlag 2009

\begin{abstract}
A large-scale field experiment on the drying behavior of Norway Spruce (Picea abies Karst.) and Sweet Chestnut (Castanea sativa Mill.) in relation to the felling date was conducted over a period of 24 weeks in order to investigate the existence of variations linked to lunar rhythms, which are mentioned as having a role in many traditional forestry practices. The measured criteria were the water loss from fresh to dry state, the shrinkage linked to this water loss, and the relative density (ratio between the dry density and the initial fresh density) for both sapwood and heartwood in Picea and heartwood in Castanea. In addition to seasonal trends, slight but significant variations with lunar periodicities (both synodic and sidereal; to
\end{abstract}

Communicated by H. Rennenberg.

\section{E. Zürcher $(\bowtie)$}

Department of Architecture, Wood and Civil Engineering,

Bern University of Applied Sciences, Solothurnstrasse 102,

P.O. Box 6071, 2504 Biel-Bienne, Switzerland

e-mail: ernst.zuercher@bfh.ch

\section{R. Schlaepfer}

Laboratory of Ecological Systems (ECOS),

Institute for Environmental Sciences and Technologies (ISTE),

Swiss Federal Institute of Technology Lausanne (EPFL)

Station 2, 1015 Lausanne, Switzerland

e-mail: Rodolphe.Schlaepfer@epfl.ch

\footnotetext{
M. Conedera Institute WSL (Forest, Snow and Landscape),

e-mail: marco.conedera@wsl.ch

F. Giudici

Federlegno Ticino, Casella Postale 280,

6902 Rivera, Switzerland

e-mail: fgiudici@federlegno.ch
}

Research Unit Ecosystem Boundaries, Swiss Federal Research

Via Belsoggiorno 22, 6500 Bellinzona, Switzerland a much lesser extent tropic) characterize the three investigated criteria. These lunar rhythmicities occur in both Picea and Castanea, in heartwood and sapwood. These results raise new questions and perspectives about a rhythmic character of the wood-water relation.

Keywords Forestry traditions - Moon phases . Technical drying $\cdot$ Wood-water relation

\section{Introduction}

Traditional knowledge and practices concerning agricultural and forestry activities-so-called rural rules-are still widely spread in various cultures on different continents (Aumeeruddy and Pinglo 1988). Among them, rules are existing about effects of the tree-felling date on the properties of wood (Hauser 1973; Broendegaard 1985; M. J. Balik and C. M. Peters, personal communication, Institute of Economic Botany, New York, 1998; R. A. A. Oldeman, personal communication, 1999). The first written evidence of this knowledge dates back to Theophrastus of Eresos (372-287 BC), who in his History of Plants (Vol 1, 3) states that there is an appropriate season for cutting the trees and-within the season-if cutting at the beginning of the waning moon, the wood is harder and less likely to rot. This popular knowledge has passed down to our times and to the local practices of felling trees during different moon positions depending on the specific forms of wood utilization (Zürcher 2000). Despite such a broad and antique tradition in referring to the moon phases for determining the most suitable date for agricultural (e.g., seeding) and forestry (e.g., tree-felling) activities, there are relatively few scientific research works on this topic. For an extensive scientific review about lunar periodicities in 
Biology, see Endres and Schad (1997); a more specific review about the topic "Plants and the Moon" has recently been published (Zürcher 2008).

In wood physics, the wood-water relations have been extensively studied (Skaar 1988; Navi and Heger 2005), but not yet including "time" as a possible initial, rhythmic factor of variation in the sample properties; the role of this factor appears at present mainly in the sorption hysteresis and in the viscoelastic behavior. Four publications can nevertheless be cited in relation to the apparently fluctuating plant-water relations at issue, where the time factor "Moon" plays an essential role in living vegetals. Experimental-based studies with Bean seeds (Phaseolus vulgaris) exist on the lunar cycle-dependent water uptake during immersion by a dormant reproductive material (Brown and Chow 1973; Spruyt et al. 1987). Circadian reversible fluctuation of tree stem diameter under controlled conditions was found in synchrony with tides on Norway Spruce (Zürcher et al. 1998). In his extensive foreword to G. Klein's recent book (2007) on the methodology of interpreting Bean leaf oscillations under constant conditions (an osmotic process), P. Barlow (University of Bristol, UK) demonstrates with several examples which reinterpret early published data (Kleinhoonte 1932), how these oscillations occur in tune with the tidal gravimetric variations (linked to the circadian synodic lunar rhythm).

Concerning the role of the lunar phase at the felling date, three almost simultaneous, geographically independent research studies investigate selected wood properties of Norway Spruce with 120 trees in Dresden (Triebel 1998), 60 trees in Freiburg i.Br. (Seeling and Herz 1998; Seeling 2000), and 30 trees in Zürich (Rösch 1999; Bariska and Rösch 2000). None of these three investigations, with six felling dates each, could however significantly confirm the influence of the moon-correlated felling date on the main tested wood properties. One exception is nevertheless worth mentioning: the loss of bound water in both sapwood and heartwood (Bariska and Rösch 2000) fluctuated in correlation with the moon phases. This highly significant difference was however not interpreted as relevant by the authors. The data collected from these 30 trees by Rösch (1999) were reanalyzed, regarding oven-dry wood density as a dependent variable in the same sense as water loss and shrinkage (Zürcher and Mandallaz 2001; Zürcher 2003). This approach led to encouragingly significant results on the criteria water loss, shrinkage, and relative density (oven-dry density in percent of initial fresh/"green" density).

In order to fill the existing gaps in the choice of the previous experimental felling dates and to obtain a suitable dataset for a broader statistical analysis, we set up a large (in terms of number of trees, experimental sites, and felling dates) and systematic (not hypothesis-linked felling dates) tree-felling experiment. The aim was to test the existence of a physical phenomenon of lunar-related variations in some selected wood properties as suggested by the mentioned kinds of ancient, traditional rules, and practices which are still widespread. In particular, we wanted to examine the occurence of rhythmic, time-dependent cyclic variations in the wood-water relation in correlation with three different types of moon rhythms or cycles. Moreover, different tree species (Norway Spruce and Sweet Chestnut) and different wood types (sapwood and heartwood) within the tree were analyzed separately.

\section{Materials and methods}

Selected material and collecting procedure

We selected two tree species according to (a) their importance on the timber market and the increasing interest for marketing it as "moon wood" (Norway Spruce trees, Picea abies Karst.) and (b) the long local tradition of felling it in different moon phases, depending on specific wood utilizations (Sweet Chestnut, Castanea sativa Mill.).

In total, we collected 432 Norway Spruce trees $(3 \times 144)$ from three sites located in the Swiss Alps (planted stand in previous pasture in Château d'Oex VD and stand from natural regeneration in Bergün GR) and the western part of Switzerland (planted forest stand in Marchissy/Begnins VD), and 144 Sweet Chestnut trees from Southern Switzerland (vegetative stand from coppice shoots in Quartino TI).

Before starting the tree-felling, a prismatic wood sample $\left(50 \times 50 \times 60 \mathrm{~mm}^{3}\right)$ was taken by local orthogonal incision with the chain saw (and detached from the stem with the help of a screwdriver) at $1.50-\mathrm{m}$ height simultaneously from all the 144 selected trees at each of the 4 sites (which means during the same day, 1 or 2 weeks before the start of felling). This was done in order to establish a time-independent reference collection of the wood of the sample trees.

Tree-felling took place every Monday and Thursday in the morning (10 a.m.) from October 6, 2003 to March 18, 2004, for a total of 48 felling dates. At each felling date, three of the previously selected sample trees were randomly chosen and cut. For each felled tree, two bottom, $7.5 \mathrm{~cm}$ thick stem disks (at $0.5 \mathrm{~m}$ from the soil) and two similar upper disks (at $4.5 \mathrm{~m}$ from the soil) were cut. From each sample tree, two of these disks (one from the bottom and one from above) were then immediately prepared in order to extract a prismatic diameter $7.5 \mathrm{~cm}$ wide (avoiding possibly occurring compression wood), from which both peripheral parts $(12 \mathrm{~cm}$, including sapwood and outer heartwood) were sent to the Bern University of Applied 
Sciences, Biel, Switzerland. The two remaining disks were stored under open-air drying conditions at each site for observations on the long-term behavior.

\section{Laboratory work}

In the laboratory, different wood pieces (cubes of $20 \times 20 \times 20 \mathrm{~mm}^{3}$ and prisms of $75 \times 10 \times 20 \mathrm{~mm}^{3}$ ) were cut from both sapwood and heartwood of the fresh blocks. In the case of Chestnut, only outer heartwood samples were produced, the sapwood zone being too thin (about $1 \mathrm{~cm}$ ) to allow the same type of test samples. In a certain number of received Spruce blocks, especially from the slow-grown mountain site, the sapwood zone was too thin for producing "pure" sapwood test samples with dimensions $20 \times 20 \times 20 \mathrm{~mm}^{3}$. On the other hand, some of the fast-grown Spruce blocks showed only a small inner part of clear heartwood-too thin for obtaining "pure" heartwood test samples. Similarly, some Chestnut blocks displayed ring shake, making the sampling of the cubes impossible. In these cases, the gaps were then filled with values extrapolated from the other samples of the same tree/same date with normal configuration.

The laboratory samples were tested according to international DIN/EN standards. The initial weight and the exact original dimensions were determined, and the fresh density calculated. Then water loss under a 1-week standardized soft drying climate $\left(20^{\circ} \mathrm{C}, 65 \% \mathrm{RH}\right)$, followed by a 1-week ovendrying (at $103^{\circ} \mathrm{C}$ ) until reaching constant weight was determined. For these steps during the drying process, threedimensional shrinkage was measured. Final weight and oven-dry dimensions at constant weight under $103^{\circ} \mathrm{C}$ (for the calculation of oven-dry density) were then determined.

\section{Defining moon cycles}

Three moon phase or moon cycle models (this term being used here in the sense of "hypotheses" to be tested) have been considered in this study, based on:

(1) the synodic lunar rhythm, linked to the sun-moonearth relationship: the passage of the new moon (sunmoon conjunction) through the first quarter to the full moon (sun-moon opposition), then through the third quarter to return to the initial phase represents the lunation and lasts 29.531 days; traditions speak of "waxing moon/waning moon" [German: "zunehmend/abnehmend"].

(2) the tropical lunar rhythm, related to the earth-moon relationship from a geocentric point of view; the moon's trajectory takes it higher in the sky (compared to the Earth's horizon) for 13 or 14 passages, then the movement is reversed for the other half of the tropical month, which lasts for 27.32158 days; traditions speak of "ascending moon/descending moon" [German: "aufsteigend/absteigend"].

(3) the sidereal lunar rhythm, whose periodicity is very close to the tropical one. This cycle is based on the constellations of the Zodiac in front of which our satellite passes during a rotation around the earth, which lasts exactly 27.32166 days. The highest point of the above-defined tropical cycle occurs in the constellation of Gemini, the lowest point in Sagittarius. Traditions mention specific zodiacal "signs" [German: "Tierkreiszeichen"] or groups from the 12 "signs" as having a special influence on plants. These groups correspond to the four elements "Fire/Air/ Water/Earth" considered as basic in the ancient natural systems since Empedocles (ca. 490-435 BC).

\section{Subdividing the lunar periodicities}

The first model used as a working hypothesis concerns the synodic lunar periodicity and is based on one of the most detailed indications of moon phase-related variations in botanical research. Based on two similar studies (Brown and Chow 1973; Spruyt et al. 1987), a statistical model subdividing the synodic lunar month in eight equivalent periods or levels was defined, in order to test in a more differentiated manner than generally formulated in the traditional rules, a hypothetical synodic periodicity in the variations of wood properties.

The second model tested is equally linked to the synodic lunar periodicity, but in a more global sense, with a binary subdivision in a waxing and a waning phase. The waxing phase corresponds to the previous levels $1-4$, the waning phase to the levels 5-8 (Table 1). This second model has been used for testing the type of rules of this low level of precision.

In relation to the second type of traditional rules mentioned above, a third model based on the tropical lunar periodicity was defined, classifying each felling date into an ascending or a descending period.

The fourth model was employed to explore in a similar quantitative way, if there could be any part of a real phenomenon at the origin of the curious rules related to the sidereal lunar periodicity. In order to simplify the analysis and to obtain enough data per level, the 12 zodiacal constellations (defined by astronomical convention-not to be confused with the astrological "zodiac signs") before which the moon is passing have been grouped into their traditionally ascribed four "qualities" (Table 2). According to these criteria, each felling date was chronologically placed in a specific way in each of the four defined lunar periodicities (Table 3). 
Table 1 Theoretical synodic models (Hypothesis): segmentation of the lunar month (four quarters) in eight levels (two per quarter, or circaseptan lunar week), based on the results of Brown and Chow (1973)

\begin{tabular}{|c|c|c|c|c|c|c|c|}
\hline \multicolumn{2}{|c|}{ New Moon } & \multicolumn{2}{|c|}{ D $1^{\text {st }}$ Quarter } & \multicolumn{2}{|c|}{ Full Moon } & \multicolumn{2}{|c|}{ (1) $3^{\text {rd }}$ Quarter } \\
\hline$\sqrt{2}$ & & ปn & & $\sqrt{2}$ & & $\sqrt{3}$ & \\
\hline 1 & 2 & 3 & 4 & 5 & 6 & 7 & 8 \\
\hline & 1: 1 & ig phas & & & 2: V & ig phas & \\
\hline
\end{tabular}

Partition in 2 levels: waxing and waning phases. The arrows for new moon, first quarter, full moon, and third quarter indicate that these events mark the first day of the corresponding levels $1,3,5$, and 7

Table 2 Overview of the astronomical regions crossed by the moon during a sidereal cycle

The exact position of each zodiacal constellation is indicated in degrees. The constellations are grouped in four "qualities," according to traditional rules

\begin{tabular}{|c|c|c|c|c|}
\hline $\begin{array}{l}\text { Four levels of the sidereal cycle } \\
\text { Tested }\end{array}$ & Sidereal 1 & Sidereal 2 & Sidereal 3 & Sidereal 4 \\
\hline \multirow{6}{*}{$\begin{array}{l}\text { Successive constellations crossed by the } \\
\text { moon, and their astronomical extension }\end{array}$} & Aries & Taurus & Gemini & Cancer \\
\hline & $29^{\circ}-53^{\circ}$ & $53^{\circ}-89^{\circ}$ & $89^{\circ}-117^{\circ}$ & $117^{\circ}-138^{\circ}$ \\
\hline & Leo & Virgo & Libra & Scorpio \\
\hline & $138^{\circ}-173^{\circ}$ & $173^{\circ}-219^{\circ}$ & $219^{\circ}-238^{\circ}$ & $238^{\circ}-268^{\circ}$ \\
\hline & Sagittarius & Capricorn & Aquarius & Pisces \\
\hline & $268^{\circ}-298^{\circ}$ & $298^{\circ}-326^{\circ}$ & $326^{\circ}-351^{\circ}$ & $351^{\circ}-29^{\circ}$ \\
\hline Traditional «quality», or «element» & "Fire" & "Earth" & "Air" & "Water" \\
\hline
\end{tabular}

Table 3 Attribution of the studied calendar period $(\mathrm{F}=$ successive fellings, odd numbers $=$ Mondays/even numbers $=$ Thursdays, except 24 \& $26=$ Wednesdays) to the specific levels of the three moon cycles

$M$ months, Syn synodic position (differentiated in eight levels and in two levels), Trop tropical position (two levels), Sid sidereal position (four levels)

\section{Data analysis}

Initial weight, dimensions, and density of the samples (freshly cut) were chosen as main reference parameters for testing the working hypothesis of the existence of timedependent, moon-correlated rhythmic variations in the wood-water relation. Each sample was therefore compared during the controlled drying process, with its respective values in the fresh state in order to avoid the effects of biological intra-tree and inter-tree variability. In order to obtain standardized series which are equivalent for all sites, the relative variations (in \%) around the mean value of the whole data set for each site, and separately for sapwood and heartwood series, were calculated. For Picea, this allowed us to compare the sapwood- with the heartwood- variations, the trend of a site with the others and to integrate the three regional sites into a global ("Swiss") series for the response variables "water loss," "shrinkage," and "relative density" (the ratio oven-dry density/fresh density). In addition, the time-independent general reference sample for each tree (extracted simultaneously with the other trees on a single day in each site before the felling campaign) was used for defining the "reference (oven-dry) density." This tree-specific value could be used as covariate, e.g., a variable with a partial predictive power of the obtained variations in the time-dependant drying behavior.

The statistical analysis was carried out on the complete sets of data, stemming from 144 trees per site/2 slices per tree/2 opposite sides per slice/sapwood and heartwood per side for Picea (heartwood only for Castanea). The 
contribution of a single Spruce tree was therefore four sapwood samples and four heartwood samples; a Chestnut tree produced four heartwood samples only. The addition of the standardized series of Picea gave 1728 values from sapwood, and 1728 values from heartwood, for the analysis of the criteria "water loss," "radial shrinkage," and "relative density." The same criteria were analyzed on Castanea, but with 576 values (one site and heartwood only). In some cases, the data series were not complete because of sample defects (insufficient sapwood or heartwood width in Picea, ring shakes in Castanea): in these cases, the gaps were filled by calculating the missing values as means from the available measurements of the same tree and date (avoiding any bias). In total, about $2 \%$ of the Castanea values and $15 \%$ of the Picea values were obtained by extrapolation.

The statistical analysis was carried out with a STATGRAPHICS 5Plus program, by testing the four lunar models with a multifactor ANOVA (variance) analysis (an analysis that examines the effects of two or more factors on one variable). This was done involving the factor "season" (subdivision of the 24 sampling weeks in periods of 1, 4, and 1 month for "Fall," "Winter," and "Spring," respectively), in addition to the mentioned covariate "reference density," which is time-independent.

\section{Results}

\section{General variability}

On the basis of the standardized site series, the variability along the $100 \%$ - line of each of the three response variables - can be described with the range between minimum and maximum value, and with the corresponding standard deviation. The greatest variability was found in the water loss of Spruce heartwood (range from 54.6 to 209.4/standard deviation 21.3). This is to be expected, since the transition from sapwood to heartwood varies specifically in each tree, and is not always easy to localize. On the other hand, the lowest variability was found in water loss of Sweet Chestnut (heartwood), from 78.3 to 120.3, with a standard deviation of 7.1.

The question to be dealt with by the statistical analysis is the following: can such variations (in water loss, shrinkage, and relative density) be attributed to mere random noise, or are they significantly linked to a time factor "season" and "lunar cycles," as could be expected according to traditional assertions?

\section{Influence of species and wood type}

As a first step in the data analysis, a general characterization of the wood-water relation at the level of the species

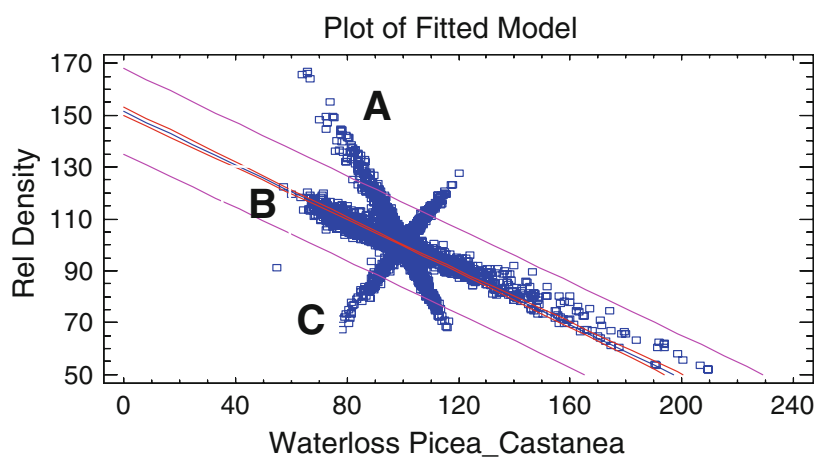

Fig. 1 Variation of the relative density as a function of the water loss (based on 4032 values). The data are represented relatively to their general mean value (100\%). The linear and negative correlation $\mathrm{A}$ is for Spruce sapwood, distinct from the same type of correlation B for Spruce heartwood. In contrast, the linear and positive correlation $\mathrm{C}$ belongs to Chestnut heartwood

brings an important orientation. If the variations of relative density (oven-dry density in $\%$ of initial fresh density) of all samples are plotted in function of the variations in water loss, remarkable linear correlations appear (Fig. 1). For Picea, two negative correlations correspond on the one hand to the sapwood samples (steep slope), on the other hand to the heartwood samples (flat slope). In contrast to this softwood, the ringporous hardwood Castanea shows a clear positive linear correlation: heartwood samples with a higher water loss develop a higher relative density. This phenomenon is possibly linked to the well-known rule that wood density is inversely proportional to ring width in softwoods (with constant latewood) but directly proportional in ringporous hardwoods (with constant earlywood), in combination with the measured very high water content of the Castanea heartwood samples. The different behavior of sapwood samples compared to heartwood samples in Picea is probably due to the higher initial water content of the first ones, linked to the fact that these tissues are partially still living (parenchyma cells), implying a difference in the wood-water relation (containing on the average more free water).

These two tree-specific types of correlations led us to perform the statistical analysis of the data from Picea separately from the Castanea ones. The relevance of this distinction will be obvious in Figs. 3 and 4, where Picea shows a fundamentally different lunar-correlated behavior than Castanea (if the variations of relative density are compared to water loss).

Influence of felling dates and related lunar phases

The general dependence of the selected wood properties from the felling date over the 24 experimental weeks ( 48 fellings) is illustrated in Fig. 2 with the means plots of 
A Means and 95.0 Percent LSD Intervals
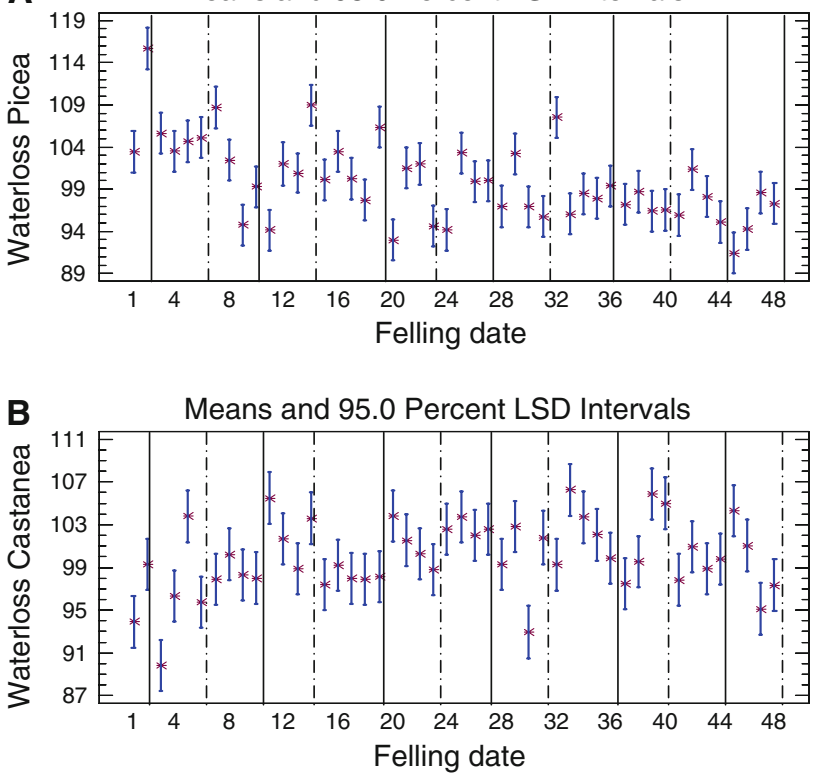

Fig. 2 General trend of the water loss around the local mean value (100\%), for Norway Spruce (a) (sapwood and heartwood, based on 3456 values) and for Sweet Chestnut (b) (heartwood, based on 576 values). Each felling date figures with a mean value and the corresponding least significant difference (LSD). The six vertical bold lines indicate the times of full moon of the research period, alternating with the times of new moon

water loss with $95 \%$ confidence intervals, involving the reference density as covariate, for Picea (global "Swiss" series sapwood and heartwood) and for Castanea (heartwood). In addition to a decreasing seasonal trend on Picea (not further presented here), strong and highly significant felling date-related variations occur, from a maximal relative value of 115.66 (SE 1.76), 26.5\% higher than the minimum 91.44 (SE 1.76). For Castanea, a slightly increasing seasonal trend is noticeable, with values differing significantly between 89.83 (SE 1.73) and 106.24 (SE 1.72), which represents a difference of $18.3 \%$.

On the upper graph A (Picea), it can already be observed that the mean values from the felling dates directly before full moon are systematically higher than the ones directly after. For Castanea (B), no such clear tendency is noticeable. In order to quantify such tendencies or to explore other types of rhythms linked to traditional assertions, the further statistical analysis successively applies the four defined models, combined with the additional factor "season" and with the covariate "reference density."

For the multifactorial variance analysis, both synodic models were applied to the full dataset of sapwood samples and of heartwood samples separately. The "total" series corresponds to the variance analysis applied on all Spruce samples, regardless whether sapwood or heartwood. In a similar way, the lunar tropical and lunar sidereal models were tested for sapwood, heartwood, and their sum (see "Total" in Table 4).

Significant and highly significant tendencies appear according to both the synodic rhythm (principally eight levels) and the sidereal rhythm. For these two rhythms, the strongest moon-related variations are observed in shrinkage, followed by relative density and water loss. Significant lunar variations are observed in heartwood samples, as they are in sapwood, but to a less strong extent. The tropical lunar rhythm on the other hand can be observed as significant only in heartwood for the criteria water loss and for relative density. The explanatory power of the lunar models was determined in the cases of significance, comparatively (in \% of the sum of squares) to the reference density. This is done as density is the most determinant physical property
Table 4 Statistical results of significance ( $P$-values) of the multifactor variance analysis (including reference density as covariate) for the criteria water loss, shrinkage, and relative density on Spruce

Significance is given when $P$ value is $<0.05(<5 \%$ risk of error, *), resp. $<0.01(<1 \%$ risk, $* *)$, and $<0.001(<0.1 \%$ risk, $* * *)$. In the case of nearsignificance $(0.10<P<0.05)$, $(*)$ is used

\begin{tabular}{|c|c|c|c|c|c|}
\hline \multicolumn{6}{|c|}{ Norway Spruce ( $P$. abies): significance of lunar rhythms } \\
\hline Lunar cycle & Wood type & $\begin{array}{l}\text { Number } \\
\text { of samples }\end{array}$ & $\begin{array}{l}\text { Water loss } \\
P \text {-value }\end{array}$ & $\begin{array}{l}\text { Shrinkage } \\
P \text {-value }\end{array}$ & $\begin{array}{l}\text { Relative density } \\
P \text {-value }\end{array}$ \\
\hline \multirow[t]{3}{*}{ Synodic eight levels } & Sapwood & 1728 & $0.0000 * * *$ & $0.0000 * * *$ & $0.0001 * * *$ \\
\hline & Heartwood & 1728 & 0.1419 & $0.0007 * * *$ & 0.1886 \\
\hline & Total & 3456 & $0.0357 *$ & $0.0000 * * *$ & $0.0026 * *$ \\
\hline \multirow[t]{3}{*}{ Synodic waxing-waning } & Sapwood & 1728 & 0.6064 & $0.0048 * *$ & 0.9172 \\
\hline & Heartwood & 1728 & $0.0179 *$ & $0.0003 * * *$ & $0.0120 *$ \\
\hline & Total & 3456 & $0.0378 *$ & $0.0000 * * *$ & 0.1401 \\
\hline \multirow[t]{3}{*}{ Tropical asc.-desc. } & Sapwood & 1728 & 0.7483 & 0.4034 & 0.4729 \\
\hline & Heartwood & 1728 & $0.0419 *$ & 0.1879 & $0.0434 *$ \\
\hline & Total & 3456 & $0.0470 *$ & 0.6876 & $0.0779(*)$ \\
\hline \multirow[t]{3}{*}{ Sidereal four levels } & Sapwood & 1728 & $0.0000 * * *$ & $0.0001 * * *$ & $0.0000 * * *$ \\
\hline & Heartwood & 1728 & 0.7389 & $0.0000 * * *$ & 0.6022 \\
\hline & Total & 3456 & $0.0759(*)$ & $0.0000 * * *$ & $0.0001 * * *$ \\
\hline
\end{tabular}


for most other physical and mechanical properties of wood. In this sense, the covariate "reference density" was found as a significant factor of variation for the three response variables. It appears that the influence of the factor "lunar rhythmicities" causes up to ca. $26 \%$ of the effect of reference density, for the criterium shrinkage according to the sidereal rhythm.

As for Picea, the multifactorial variance analysis was applied in the case of Castanea on the complete dataset specifically for each lunar model. Both synodic models could be analyzed on a sample number of 576 for the heartwood material of the Southern Alps site. In a similar way, the lunar tropical and lunar sidereal models could be tested on this set of samples. Table 5 indicates the degree of significance of the tested models applied to the three criteria water loss, shrinkage, and relative density.

Significant tendencies appear only according to the sidereal rhythm, for water loss and relative density, whereas shrinkage is varying at the limit of near-significance. For the 8-level synodic rhythm, the moon-related variations are near-significant in shrinkage alone. The tropical lunar rhythm plays no role in the variations of Castanea heartwood drying behavior.

The explanatory power of the lunar models in the cases of significance and near-significance was also calculated for the full series, comparatively (in \% of the sum of squares) to the reference density. The influence of the factor "lunar rhythmicities" is reaching maximally ca. $10 \%$ for water loss and relative density in the case of the significant sidereal rhythm. One case of the near-significant models, namely synodic with eight levels, has an explanatory power of about $50 \%$ of the effect of the reference density on the shrinkage behavior.

The comparative graphic representation (Fig. 3) of the variations in the three response variables for Picea and Castanea according to the synodic lunar model (eight levels) illustrates some remarkable facts:
- A strong opposite rhythmicity is observed between relative density and water loss in Picea, whereas in Castanea, the variations of these two criteria are parallel; this is coherent with the overall correlations appearing in Fig. 1.

- A certain similarity in the variations of shrinkage is noticeable between Picea and Castanea.

- For Picea, the most extreme value in water loss (minimum) and in relative density (maximum) corresponds to the synodic level 5 , which covers the $3 \frac{1}{2}$-day period beginning at the day of the full moon. On the other hand, no such dramatic change near full moon is shown in Castanea: here, it is observed simultaneously at synodic level 2, the 31/2-day period before the First Quarter.

- The waning period (synodic level 5-8) of Picea shows a stronger shrinkage than the waxing period; this is tendentially also the case for Castanea.

- An interesting coherence between the lunar variabilities of the analyzed criteria appears in comparison among the tree species, in the form of parallel, resp. opposite tendencies despite the fact that for some cases, only near-significance was obtained.

- However, it must be emphasized that the differences between the extreme mean values are relatively weak: for Picea water loss $3.2 \%$, relative density $2.8 \%$, and shrinkage $4.9 \%$; for Castanea, the maximal relative difference occurs in shrinkage with $6.6 \%$.

The variations occurring in phase with the sidereal rhythm (a scientifically much less explored field) present the same type of interrelations as the synodic ones (Fig. 4). Relative density is opposite to water loss for Picea, but parallel for Castanea, again in accordance with Fig. 1. Shrinkage in Castanea varies again in a similar way as in Picea, where the maximum value coincides with the maximum in relative density and with the minimum in water loss (sidereal level 3). Here as well, a strong species-specific

Table 5 Statistical results of significance ( $P$-values) of the multifactor variance analysis (including reference density as covariate) for the criteria water loss, shrinkage, and relative density on Sweet Chestnut

\begin{tabular}{|c|c|c|c|c|c|}
\hline \multicolumn{6}{|c|}{ Sweet Chestnut (Castanea sativa): significance of lunar rhythms } \\
\hline \multicolumn{6}{|c|}{ 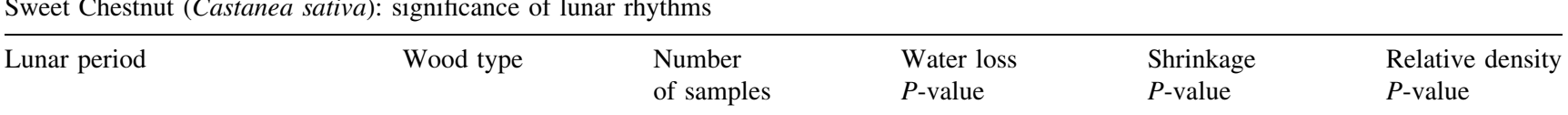 } \\
\hline \multicolumn{6}{|l|}{ Synodic eight levels } \\
\hline Synodic waxing-waning & Heartwood & 576 & 0.8983 & 0.2184 & 0.7731 \\
\hline Tropical asc.-desc. & Heartwood & 576 & 0.5372 & 0.3388 & 0.5666 \\
\hline Sidereal four levels & Heartwood & 576 & $0.0298 *$ & $0.0844(*)$ & $0.0160 *$ \\
\hline
\end{tabular}

Significance is given when $P$-value is $<0.05$ ( $<5 \%$ risk of error, $*)$. In the case of near-significance $(0.10<P<0.05)$, (*) is used 

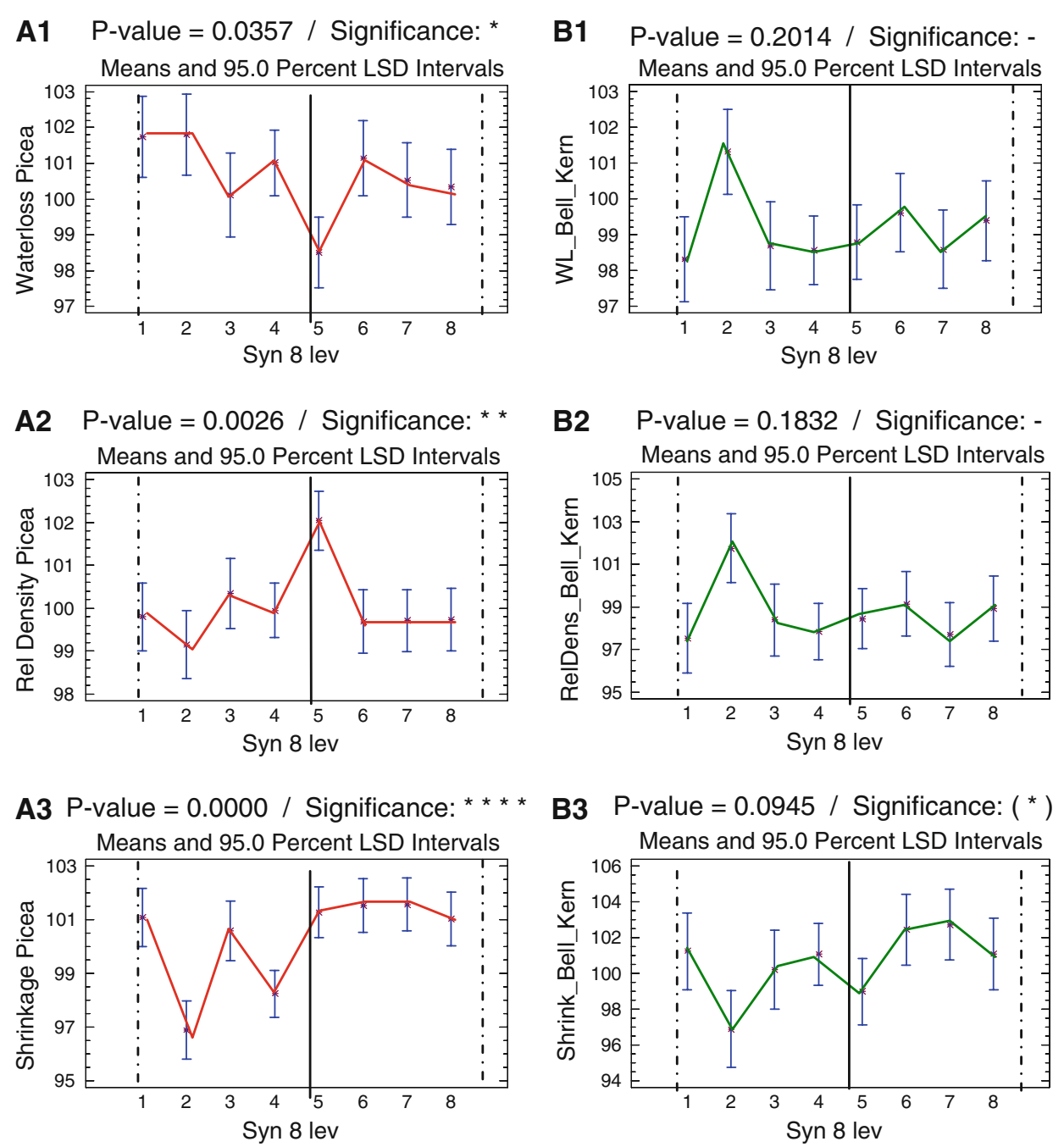

Fig. 3 Lunar synodic variations of water loss (1), relative density (2), and shrinkage (3) of Norway Spruce (sapwood and heartwood, a) and of Sweet Chestnut samples (heartwood, b), when dried from "fresh" to oven-dry state. Mean values with $95 \%$ least significant differences. The vertical bold lines indicate the times of full moon, the dotted lines the times of new moon. Distribution of the numbers of samples

\begin{tabular}{|l|c|c|c|c|c|c|c|c|c|}
\hline Syn. levels & 1 & 2 & 3 & 4 & 5 & 6 & 7 & 8 & Total \\
\hline Picea & 360 & 360 & 360 & 576 & 504 & 432 & 432 & 432 & 3456 \\
\hline Castanea & 60 & 60 & 60 & 96 & 84 & 72 & 72 & 72 & 576 \\
\hline
\end{tabular}

coherence in the variabilities is distinguishable, independent of the obtained $P$-values.

\section{Discussion}

During the investigation period (and particularly in the season marked by tree-physiological stagnation), it can be assumed that no short-term and reversible changes in the stem's water content are occurring. This is especially true for the heartwood. Therefore, the significantly varying water loss with regard to the felling date is not to be interpreted as a consequence of a varying initial humidity.
It is rather the consequence of an easier water extraction during the drying process of samples from specific synodic or sidereal lunar periods, compared to a more difficult, reduced water extraction from samples obtained in other periods. Such a result demonstrates the reality of the phenomenon statistically observed on the variations of bound water in both sapwood and heartwood of Picea (Bariska and Rösch 2000). This interpretation could be consistent with the recently discovered circadian diameter fluctuations ("tree tides") — a lunar rhythmicity at the daily level (Zürcher et al. 1998), probably coupled with rhythmic bioelectric variations (Holzknecht 2002; Holzknecht and Zürcher 2006). The phenomenon had been interpreted in a 

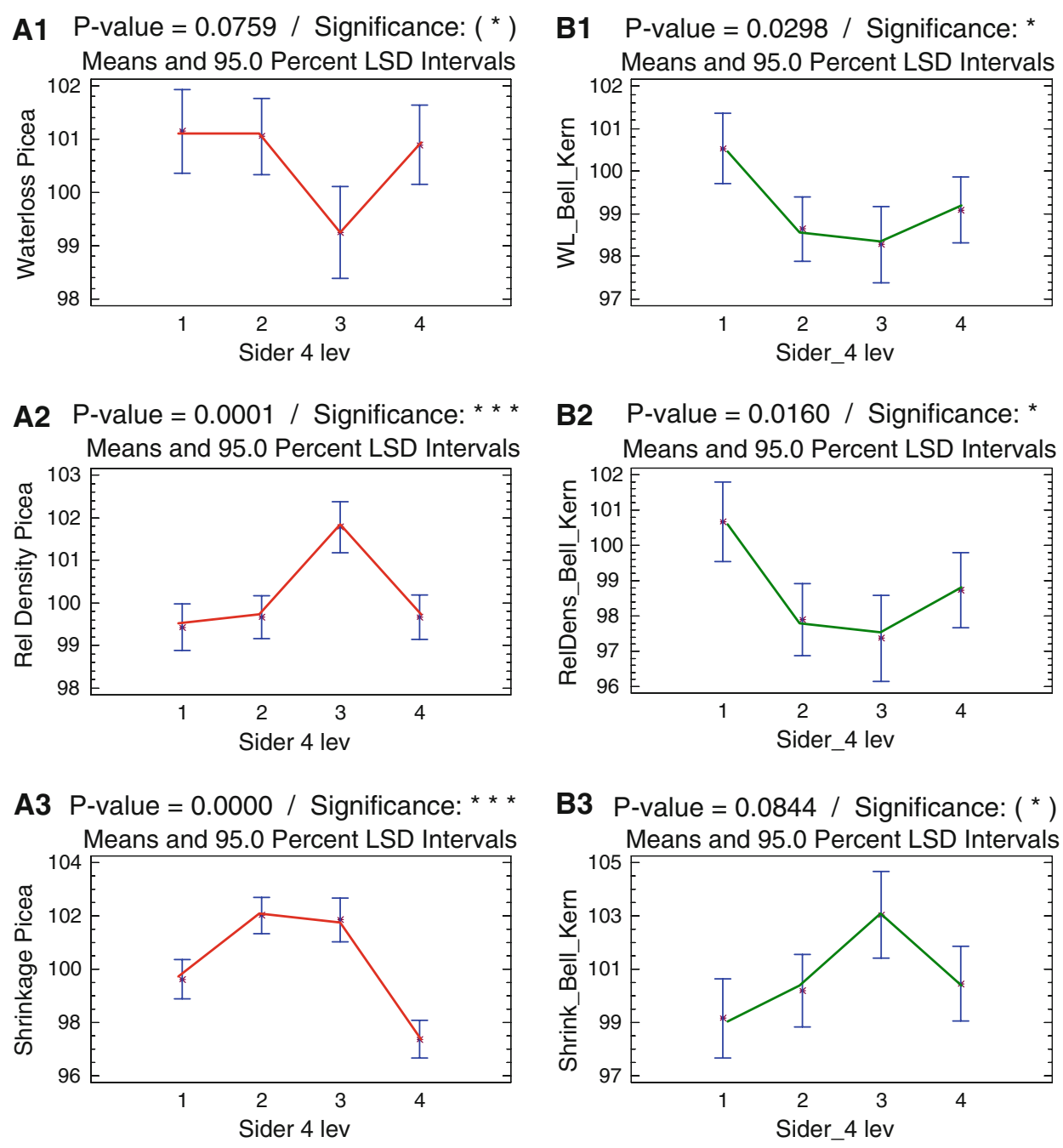

Fig. 4 Lunar sidereal variations of water loss (1), relative density (2), and shrinkage (3) of Norway Spruce (sapwood and heartwood, a) and of Sweet Chestnut samples (heartwood, b), when dried from "fresh" to oven-dry state. Mean values with 95\% least significant differences. Correspondence of the four levels to zodiacal constellations: see Table 2. Distribution of the numbers of samples

\begin{tabular}{|l|c|c|c|c|c|}
\hline Sidereal levels & 1 & 2 & 3 & 4 & Total \\
\hline Picea & 792 & 1080 & 648 & 936 & 3456 \\
\hline Castanea & 132 & 180 & 108 & 156 & 576 \\
\hline
\end{tabular}

similar way as a result of water movements between symplast and apoplast.

The highly significant synodic rhythmicity of water loss in Picea (based on a sixfold number of samples than from Castanea) shows an interesting analogy to the one of the Bean seed water uptake discovered by Brown and Chow (1973), which is the base of our model. This alternance of relative minima and maxima is also weakly visible in Castanea.

Also noticeable is that the shrinkage measured during the drying process varies significantly, in the sapwood as well as in the heartwood. It is interesting to note that for both wood types in Picea, data with higher water loss show a relatively low shrinkage coupled with low relative density, and vice versa. With this special investigative order, values and relations are achieved which do not correspond to the general rule of shrinkage being always proportional to the loss of water. The same phenomenon can be distinguished for specific dates in the Dresdner investigation (Triebel 1998), as in comparative Picea fellings 1 year later in Freiburg i.Br. (Seeling and Herz 1998), which also show that sapwood samples from specific moon-related dates can have a higher water loss than the preliminary and succeeding alternative moon-related samples and nonetheless have a significantly lower shrinkage. 
These facts indicate a reversible modification of the wood-water relationship (binding of water in the cell wall). The ratio between the proportion of free water and the proportion of capillary, electrostatically, and hydrogenbound water may therefore not be constant, possibly due to the formation of variable supra-molecular organizational units. A new theoretical fundamental basis for such reversible fluctuations in "water clusters" is recently proposed by Dorda (2004), co-author with K. von Klitzing of the discovery of the "Quantum-Hall Effect". Dorda's postulated fluctuations of the supra-molecular aggregation of water are modulated by the sun-earth interaction and simultaneously by the moon-earth interaction, with effects at all levels of living systems. This new general model of dynamic gravitation enabled this author to confirm mathematically the tidal (daily synodic) fluctuations described on young Spruce trees held under constant conditions (based on data from Zürcher et al. 1998).

According to the first modern scientific works on the influence of the timing of tree-felling on the durability of wood against fungal decay (Gäumann 1930), significant seasonal variations occur for sapwood as well as for heartwood samples. It was admitted that this is due to a varying colloid-chemical state of cell-wall cellulose and hemicellulose in the different seasons of the year. This interpretation can be supported by later research on Oak wood samples taken from standing trees (Burmester 1978a, b), according to which the moisture saturation point of the fibers of the (normally considered as "dead") heartwood significantly varied over the course of the year (with one of the minimal values in December). Our findings can be considered as a further confirmation of such a type of fluctuations in the physical properties of wood in relation to water, adding to the seasonal variation factor (an earth-sun relationship) a complementary factor acting in shorter periods: the earth-moon relationship mainly in two of its forms: synodic and sidereal. One of the very remarkable, already observed facts (Zürcher and Mandallaz 2001) is that the lunar-correlated processes are not limited to peripheral, water-saturated, and living sapwood: they can as well be observed in the inner, drier, and non-living heartwood (however, mostly to a lower extent).

As stated for Picea, the most extreme value in water loss (minimum) and in relative density (maximum) corresponds to the synodic $3 \frac{1}{2}$-day period starting at the day of the full moon: the first days of the waning moon, as mentioned by Theophrastus. As no such dramatic change is shown at this period in Castanea, the question arises as to whether the validity of some traditional rules is possibly limited to defined tree species or groups of species. The significantly higher shrinkage values obtained on Spruce samples from the waning moon period (and a tendency in the same sense for Chestnut) attest the reality of this time-factor mentioned in many rules. Yet an important difference is that in our findings, the shrinkage is greater instead of less when trees are felled in this period. Further tests should determine if after a first drying, such woods are hygroscopically and dimensionally still less stable than samples from the waxing moon, or are possibly less subject to a new water uptake.

\section{Future research}

This investigation describes a scientifically as yet unknown phenomenon concerning wood physics, although it has long been mentioned in various cultures. It must be seen as a first step - the processes leading to this phenomenon and the related conditions will have to be investigated in detail. These first large-scale results however do not permit the estimation of the practical validity of single traditional rules: here too, further research is needed, especially on dimensional stability under changing hygrometry and concerning the effect on wood durability against decay, as has already been done conclusively on Palm leaves (Vogt et al. 2002).

Acknowledgments This research was supported by funds provided by Wolfermann-Nägeli-Foundation Zürich, Chambre des Bois de l'Ouest Vaudois, Sezione Forestale Cantonale (Ticino), Federlegno Ticino, Graubünden Holz (Amt für Wald Mittelbünden), Kantonsforstamt Schwyz, Schwyzer Arbeitsgemeinschaft HOLZ, Kloster Einsiedeln SZ, and Thoma Holz GmbH (Austria). The realization occurred with the collaboration of Christian Rogenmoser, Dr. Thomas Volkmer, Werner Gerber, Andrea Florinett, Christian Barandun, Eric Treboux, Denis Pidoux, Serge Lüthi, Christophe Rémy, Daniel Meyer, Marco Delucchi, Theo Weber, Dr. Joan Davis.

\section{References}

Aumeeruddy Y, Pinglo F (1988) Phytopractices in tropical regions. UNESCO/Man and the Biosphere, Montpellier, $71 \mathrm{pp}$

Bariska M, Rösch P (2000) Felling date and shrinkage behaviour of Norway Spruce. Schweiz Z Forstwes 11:439-443 (in German, English summary)

Broendegaard VJ (1985) Ethnobotany: plants in traditions, history and popular medicine-tree felling and moon phases: superstition or folk-visdom? In: Contributions to ethnomedicine, ethnobotany and ethnozoology. Verl. Mensch und Leben, Berlin, vol 6, pp 82-92 (in German)

Brown FA, Chow CS (1973) Lunar-correlated variations in water uptake by bean seeds. Biol Bull 145:265-278

Burmester A (1978a) Annual variations in shrinkage and swelling of Oak wood in living trees. Holz Roh-Werkst 36:157-161 (in German)

Burmester A (1978b) Annual variations of physical wood properties in an Oak tree (Quercus robur L.). Holz Roh-Werkst 36:315-321 (in German)

Dorda G (2004) Sun, earth, moon-the influence of gravity on the development of organic structures. Part II: the influence of the moon. Sudetendeutsche Akademie der Wissenschaften und Künste, München, vol 25, pp 29-44 
Endres K-P, Schad W (1997) Biology of the moon. Moon periodicities and life rhythms. S. Hirzel Verlag, Stuttgart, 308 pp (in German)

Gäumann E (1930) Research on the influence of the felling time on the wood properties of Norway Spruce and Silver Fir. 2. Teil. Beiheft Nr.5, Zeitschriften des Schweizerischen Forstvereins, $155 \mathrm{pp}$ (in German)

Hauser A (1973) Rural rules. A Swiss collection with comments. Artemis Verlag, Zürich, 710 pp (in German)

Holzknecht K (2002) Electrical potential in the sapwood of Norway spruce (Picea abies L.) and stone pine (Pinus cembra L.) and their relationship with climate and lunar phase. Phd thesis G0443 Physiology, Universitaet Innsbruck, Naturwissenschaftliche Fakultaet, Institut fuer Botanik, 124 pp (in German, English summary)

Holzknecht K, Zürcher E (2006) Tree stems and tides-a new approach and elements of reflexion. Schweiz Z Forstwes 157(6):185-190

Klein G (2007) Farewell to the internal clock. A contribution in the field of chronobiology. Springer, New York, $116 \mathrm{pp}$

Kleinhoonte A (1932) Research on the autonomous movements of the primary leaves of Canavalia ensiformis DC. Jahrbücher für wissenschaftliche Botanik 75:679-725 (in German)

Navi P, Heger F (2005) Thermo-hydromechanical behavior of wood. Presses Polytechniques et Universitaires Romandes, Lausanne, 298 pp (in French)

Rösch P (1999) Research on the influence of the moon phase-related felling date on the drying process and shrinkage of Norway Spruce-wood (Picea abies Karst.). Diploma thesis, Swiss Federal Institute of Technology, Wood Sciences, Zürich, 42 pp (in German, English summary)

Seeling U (2000) Selected wood properties of Norway Spruce (Picea abies L. Karst) and its dependance on the date of felling. Schweiz Z Forstwes 151(11):451-458 (in German, English summary)
Seeling U, Herz A (1998) Influence of felling date on shrinkage and water content of Norway Spruce-wood (Picea abies Karst.). A literature survey and pilot research. Albert-Ludwigs-University, Forest Sciences, Freiburg i.Br., 98 pp (in German)

Skaar C (1988) Wood-water relations. Springer, Berlin, 283 pp

Spruyt E, Verbelen J-P, De Greef JA (1987) Expression of circaseptan and circannual rhythmicity in the imbibition of dry stored bean seeds. Plant Physiol 84:707-710

Triebel J (1998) Moon phase-dependent tree-felling-a literature survey and research on some properties of Norway Spruce (Picea abies Karst.). Technical University of Dresden, Forest Sciences, Tharandt, $108 \mathrm{pp}$ (in German)

Vogt KA, Beard KH, Hammann S, O'Hara Palmiotto J, Vogt DJ, Scatena FN, Hecht BP (2002) Indigenous knowledge informing management of tropical forests: the link between rhythms in plant secondary chemistry and lunar cycles. Ambio 31(6):485490

Zürcher E (2000) Moon-related traditions in forestry and corresponding phenomena in tree biology. Schweiz $\mathrm{Z}$ Forstwes 151(11):417-424 (in German, English summary)

Zürcher E (2003) Drying and weathering behaviour of Norway Spruce (Picea abies Karst.) wood felled according to moon phase. Schweiz Z Forstwes 154(9):351-359 (in German, English summary)

Zürcher E (2008) Les Plantes et la Lune-traditions et phénomènes. In: Hallé F (ed) Aux Origines des Plantes-Des plantes anciennes à la botanique du XXIè siècle. Arthème Fayard, Paris, pp 388-411

Zürcher E, Mandallaz D (2001) Lunar synodic rhythm and wood properties: traditions and reality. Experimental results on Norway Spruce (Picea abies Karst.). In: Proceedings of the 4th international symposium, Tree Biology and Development. Isabelle Quentin Publication, Montreal, pp 244-250

Zürcher E, Cantiani M-G, Sorbetti Guerri F, Michel D (1998) Tree stem diameters fluctuate with tide. Nature 392:665-666 